\title{
Haemodynamic changes during a squat test, pulsatile stress and indices of cardiovascular autonomic neuropathy in patients with long-duration type 1 diabetes
}

\author{
J.-C. Philips, M. Marchand, A.J. Scheen \\ CHU Sart Tilman, University of Liège, Division of Diabetes, Nutrition and Metabolic Disorders, Department of Medicine, 4000 Liège, \\ Belgium
}

\begin{abstract}
Aim. - Cardiovascular autonomic neuropathy (CAN) and pulsatile stress are considered to be independent cardiovascular risk factors. This study compared haemodynamic changes during an active orthostatic test in adult patients with type 1 diabetes (T1DM), using low versus high RR E/I ratios as a marker of CAN.
\end{abstract}

Methods. - A total of 20 T1DM patients with low RR E/I ratios were compared with 20 T1DM patients with normal RR E/I ratios, matched for gender (1/1 ratio), age (mean: 46 years) and diabetes duration (22-26 years); 40 matched healthy subjects served as controls. All subjects were evaluated by continuous monitoring of arterial blood pressure (Finapres ${ }^{\circledR}$ ) and heart rate using a standardized posture test (1-min standing, 1-min squatting, 1min standing), thus allowing calculation of baroreflex gain.

Results. - Compared with controls, T1DM patients showed lower RR E/I ratios, reduced baroreflex gains, higher pulsatile stress (pulse pressure $\times$ heart rate), greater squatting-induced pulse pressure rises, orthostatic hypotension and reduced reflex tachycardia. Compared with T1DM patients with preserved RR E/I ratios, T1DM patients with low RR E/I ratios showed reduced post-standing reflex tachycardia and baroreflex gain, and delayed blood pressure recovery, but no markers of increased pulsatile stress. Interestingly, decreased baroreflex gain was significantly associated with both pulsatile stress and microalbuminuria.

Conclusion. - The use of RR E/I ratios to separate T1DM patients allows the detection of other CAN markers during an orthostatic posture test, but with no significant differences in pulsatile stress or microalbuminuria. In this context, squatting-derived baroreflex gain appears to be more informative.

Keywords : Baroreflex gain ; Cardiac autonomic neuropathy ; Pulse pressure ; Squatting ; Type 1 diabetes

\section{Résumé}

Modifications hémodynamiques lors d'un test d'accroupissement, stress pulsatile et indices de neuropathie autonome cardiovasculaire chez des patients diabétiques de type 1 de longue durée d'évolution.

But. - La neuropathie autonome cardiaque (NAC) et le stress pulsatile sont considérés comme des facteurs de risque cardiovasculaire indépendants. Nous avons comparé les modifications hémodynamiques pendant un test actif d'orthostatisme chez des adultes diabétiques de type 1 (DT1) séparés selon la valeur de RR E/I ratio (basse versus élevée) comme marqueur de NAC.

Méthodes. - Vingt patients DT1 avec un ratio E/I abaissé ont été comparés à 20 patients DT1 avec un ratio E/I normal, appariés pour le sexe (1/1 ratio), l'âge (moyenne : 46 années) et la durée du diabète (22-26 années). Quarante sujets sains appariés ont servi de témoins. Tous les sujets ont été évalués par une mesure continue de pression artérielle (Finapres ${ }^{\circledR}$ ) et de fréquence cardiaque lors d'un test postural standardisé (une minute debout, une minute accroupi, une minute debout) avec calcul d'un gain baroréflexe.

Résultats. - Comparés aux témoins, les patients DT1 ont un ratio E/I abaissé, un gain baroréflexe diminué, un stress pulsatile (pression puisée $\times$ fréquence cardiaque) accru, une augmentation plus marquée de pression puisée en position accroupie, une hypotension orthostatique et une tachycardie réflexe réduite. Comparés aux patients DT1 avec un ratio E/I préservé, les patients DT1 avec un ratio E/I abaissé ont une diminution de la tachycardie réflexe lors du redressement et une réduction du gain baroréflexe, un retard dans la correction de l'hypotension orthostatique, mais pas d'augmentation du stress pulsatile. Il est intéressant de noter que la diminution du gain baroréflexe est significativement associée au stress pulsatile et à la microalbuminurie.

Conclusion. - L'utilisation du rapport RR E/I pour séparer les patients DT1 permet de détecter d'autres marqueurs de NAC durant un test d'orthostatisme, mais sans différences significatives en ce qui concerne le stress pulsatile ou la microalbuminurie. De ce point de vue, le gain baroréflexe calculé lors du passage accroupi- 
debout apparaît plus discriminant.

Mots clés : Diabète de type 1 ; Gain baroréflexe ; Neuropathie autonome cardiaque ; Pression puisée ; Squatting

\section{Introduction}

Cardiovascular autonomie neuropathy (CAN) is a common complication of diabetes, especially in patients with long-duration type 1 diabetes mellitus (T1DM) [1-4]. Of the initial battery of tests to assess CAN [5], the easiest, most informative and most popular marker in clinical practice is the R-R interval expiration/inspiration (RR E/I) ratio, measured during a deep-breathing test [6]. According to a recent experts' review [4], this index has the highest specificity (80\%) in the detection of CAN. In a French population of T1DM patients, the total prevalence of CAN assessed by three standard tests averaged $51 \%$, with $4.8 \%$ having severe CAN and $18.2 \%$ having moderate CAN [7]. Patients with T1DM are also characterized by accelerated arterial stiffness [8], which results in increased systolic blood pressure (SBP) and pulse pressure (PP) [9]. Both CAN [10] and increased PP [11,12] are considered to be independent risk factors of cardiovascular disease and total mortality in T1DM patients. Furthermore, CAN may be linked to aortic stiffness [13,14], endothelial dysfunction [15] and increased SBP [16] or PP [17] in T1DMpatients. Moreover, CAN is known to be associated with a greater risk of orthostatic hypotension $[18,19]$.

The squat test is a posture manoeuvre that can be used to assess orthostatic hypotension [20,21], CAN [17,22,23] and pulsatile stress $[17,24]$ in patients with diabetes. Using this posture test, and continuous monitoring of BP and heart rate (HR), it was recently demonstrated that: the squatting position amplifies PP increases in T1DM patients [24] ; PP and the product of PP $\times$ HR (so-called 'pulsatile stress') increase more rapidly with age in T1DM patients than in non-diabetic controls $[17,25]$; and pulsatile stress in middle-aged T1DM patients is similarly increased as that measured in age-matched patients with type 2 diabetes and the metabolic syndrome [26]. Careful analysis of the accompanying changes in SBP and HR during the squatting-standing transition allows calculation of a baroreflex gain, similar to the barosensitivity index derived from a pharmacological test using a combination of vasodilator/vasopressor agents [17,27].

The aims of the present study were: (1) to investigate haemo-dynamic changes, pulsatile stress and CAN indices (including baroreflex gain) during a squat test in T1DM patients compared with non-diabetic controls matched for gender, age and body mass index (BMI); (2) to compare the results in T1DM patients separated on the basis of the classical RR E/I ratio (decreased vs maintained) after matching for gender, age, BMI and duration of diabetes; and (3) to compare the relationships between baroreflex gain versus RR E/I ratio, pulsatile stress and microalbuminuria in T1DM patients.

\section{Research design and methods}

\subsection{Patients}

From our database, 20 T1DM patients (10 men and 10 women) with the lowest RR E/I ratios evaluated during a classical deep-breathing manoeuvre were selected, and compared with 20 T1DM patients (10 men and 10 women) with the highest RR E/I ratios. All of the patients were matched for age, BMI and duration of diabetes. Those with arterial hypertension, renal insufficiency or cardiovascular disease, or who were taking medications interfering with vascular reactivity (including any type of antihypertensive agents except for renin-angiotensin system blockers taken for microalbuminuria), were excluded from the study. All T1DM patients received intensified insulin therapy, comprising either four daily injections according to a basal-bolus scheme $(n=35)$ or continuous subcutaneous insulin infusion (CSII) using a portable pump $(n=5)$. Also, 40 non-diabetic subjects matched for gender (ratio: 1/1), age (25-60 years) and BMI (20-30 kg/ $\left.\mathrm{m}^{2}\right)$ served as controls.

The study protocol was accepted by our institution's ethics committee.

\subsection{Dynamic tests}

Slow deep-breathing (six breaths/min) over 3 min was performed by each subject to evaluate respiration-induced HR variability, which was assessed by measuring the classical RR E/I ratio [5], corresponding to the ratio between the longest R-R interval during the expiration (E) phase and the shortest R-R interval during the inspiration (I) phase. While CAN is classically defined as the presence of several abnormalities arising from a battery of tests [5], the RR E/I ratio is thought to have the greatest specificity [4]; it has been reported that knowledge of the degree of CAN, as defined by reduced HR variability, is not significantly increased when other functional tests are added to the RR E/I ratio [6]. 
The squat test (1 min of standing, 1 min of squatting and 1 min of standing again, in succession) is the original active orthostatic manoeuvre that leads to the most important and rapid variations in hydrostatic levels with posture [28]. Squatting produces a prompt increase in cardiac output and arterial BP, essentially attributed to the augmented venous return due to compression of the leg veins. These changes result in a significant increase in mean arterial BP (MBP) and PP [17,24], which is accompanied by an immediate decrease in HR and forearm vascular resistance, probably due to activation of cardiopulmonary and arterial baroreflexes, thus implicating the autonomic nervous system. Also, the active transition from squatting to standing results in a profound initial BP decrease, inducing reflex tachycardia that can be used to detect diabetic CAN [22] and assess baroreflex sensitivity [23,27].

\subsection{Measurements}

Changes in SBP, diastolic blood pressure (DBP) and HR were measured continuously with a Finapres ${ }^{\circledR}$ (finger arterial pressure) instrument (Finapres Medical Systems B.V., Amsterdam, The Netherlands), allowing careful study of cardiovascular reflexes especially during an orthostatic manoeuvre [29]. The Finapres ${ }^{\circledR}$ device is based on servo-plethysmomanometry, using the volume clamp technique on the finger. Good concordance has been reported between Finapres ${ }^{\circledR}$ BP measurements and direct intra-arterial measurements [29]. PP (SBP minus DBP) was automatically calculated throughout the test. MBP was calculated by the formula [SBP $+(2 \times \mathrm{DBP}) / 3$ ]. Pulsatile stress was defined as the product of PP and HR, which has been shown to be largely regulated by arterial stiffness and sympathetic nerve activity, and associated with a higher risk of (micro)albuminuria [30]. For each variable or parameter, mean levels were calculated for each subject during the whole of the test period (3 min) and during each 1-min posture, after exclusion of the initial transition phase, as previously described $[17,24]$.

During the transition from squatting to standing, there was an abrupt drop in BP associated with reflex tachycardia, followed by rapid return to baseline values of both parameters (BP increase and HR decrease). The associated changes in HR and SBP allowed calculation of baroreflex gain ( $\mathrm{ms}_{\mathrm{mmHg}} \mathrm{mm}^{-1}$ ) by plotting the pulse intervals (R-R) against SBP values, with the slope of this relationship representing baroreflex sensitivity [27]. Also calculated were both the so-called 'vagal index' ( $\mathrm{SqT}_{\mathrm{v}}$ : ratio between the baseline cardiac R-R interval and the longest R-R interval during the first $15 \mathrm{~s}$ of squatting) and the so-called 'sympathetic index' (SqT: ratio between the baseline cardiac R-R interval and the shortest R-R interval during the first 10-20 s of standing after squatting), as previously described [22]. These indices, based on HR reduction during squatting and reflex tachycardia during standing, were considered markers of CAN, wherein a higher $\mathrm{SqT}_{\mathrm{v}}$ value indicates parasympathetic neuropathy while a lower $\mathrm{SqT}_{\mathrm{s}}$ is an indicator of sympathetic neuropathy [22,23].

Concomitant glycated haemoglobin $\left(\mathrm{HbA}_{1 \mathrm{c}}\right.$ ) levels (normal values 4-6\%) were measured to assess recent blood glucose control in the diabetic patients; for each patient, their corresponding $\mathrm{HbA}_{1 \mathrm{c}}$ mean level was the average of one to three measurements.

Incipient nephropathy was defined as the presence of an increased albumin excretion rate or either microalbuminuria (30-300 mg/L) or mild proteinuria (300-600 mg/L), as measured by the standard methods.

\subsection{Statistical analysis}

Sample sizes of 19 in each group were required to achieve an 80\% power to detect a difference in mean PP of 12 $\mathrm{mmHg}$, assuming that the standard deviation (SD) was $13 \mathrm{mmHg}$, using a two-sided z test with a 0.05 significance level. A difference of $12 \mathrm{mmHg}$ was deemed clinically significant, as this was shown to be associated with an increased total mortality in the large EURODIAB cohort of T1DM patients [12]. The 13mmHg SD was derived from previous studies by our group in both non-diabetic subjects and T1DM patients $[17,25]$. Between-group differences were analyzed using unpaired $t$ tests. The relationship between two variables, such as pulsatile stress and baroreflex gain, was assessed by the Spearman correlation coefficient. Results were expressed as means \pm SD values for all continuous variables. Because of a skewed distribution, microalbuminuria was also expressed by median and interquartile values. A $P$ value $<0.05$ was considered significant.

\section{Results}

\subsection{Type 1 diabetes mellitus (T1DM) patients versus non-diabetic subjects}

The demographic characteristics of the 40 T1DM patients and 40 control subjects are summarized in Table 1. The two groups were matched for gender (1/1 ratio), age and BMI. BP levels were comparable in the two groups. However, PP tended to be slightly higher and HR significantly higher in T1DM patients compared with the controls, such that the pulsatile stress index $(\mathrm{PP} \times \mathrm{HR})$ was significantly increased in the presence of diabetes versus non-diabetics (5011 \pm 1112 vs $4303 \pm 994 \mathrm{mmHg} \cdot \mathrm{min}^{-1}$, respectively; $\left.P=0.004\right)$. The squatting position 
was associated with a two-fold greater PP rise in T1DM patients than in the controls (Fig. 1, left; Table 1). Also, the maximum drop in MBP during the transition from squatting to standing was greater in T1DM patients than in the controls, while the return to baseline values also tended to be delayed. Furthermore, the immediate reflex tachycardia was significantly lower in T1DM patients compared with the controls.

RR E/I ratios were significantly lower in T1DM patients than in the age-matched control subjects. However, the parasympathetic $\mathrm{SqT}_{\mathrm{v}}$ and sympathetic $\mathrm{SqT}_{\mathrm{s}}$ indices of CAN, measured during the squat test, were not significantly different between the two groups. It is worth noting, nevertheless, that the baroreflex gain calculated during the transition from squatting to standing was lower in T1DM patients than in the controls (1.91

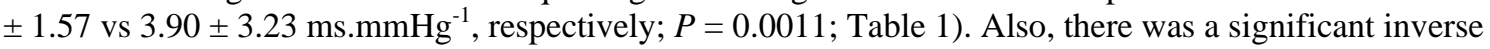
correlation between baroreflex gain and pulsatile stress in the combined cohort of 40 T1DM patients and 40 controls ( $r=-0.3363 ; P=0.0023)$, but not between RR E/I ratios and pulsatile stress $(r=0.1105 ; p=0.4049)$.

\subsection{Type 1 diabetes mellitus (T1DM) patients with low versus high RR E/I ratios}

The demographic characteristics of the 20 T1DM patients with low RR E/I ratios (1.05 \pm 0.02$)$ and the 20 T1DM patients with high RR E/I ratios $(1.27 \pm 0.10)$ are summarized in Table 2 . The two groups were matched for gender (1/1 ratio), age, $\mathrm{BMI}$ and diabetes duration. $\mathrm{HbA}_{1 \mathrm{c}}$ levels did not significantly differ between the two groups. Mean and median microalbuminuria levels tended to be higher in patients with low RR E/I ratios than in those with high RR E/I ratios (Table 2).

Overall, the mean BP and PP levels were comparable in the two diabetic subgroups. However, HR tended to be higher throughout the test in T1DM patients with low RR E/I ratios versus those with high RR E/I ratios, but the difference was not significant. Likewise, no significant differences were observed between the two subgroups in $\mathrm{PP}$ and pulsatile stress $(\mathrm{PP} \times \mathrm{HR})$ indices. The squatting position was associated with significant rises in mean $\mathrm{BP}$ and PP, and decreases in HR, in the two groups, with no significant differences between T1DM patients with either low or high RR E/I ratios (Fig. 1, right; Table 2). However, the reflex-driven abrupt rise in HR during the transition from squatting to standing was significantly lower in T1DM patients with low compared with high RR E/I ratios. The maximum drop in MBP during the transition from squatting to standing was also similar in the two groups. However, the delay in recovery back to initial baseline MBP levels was significantly increased in T1DM patients with low RR E/I ratios compared with those of patients with high RR E/I ratios (Table 2).

$\mathrm{SqT}_{\mathrm{v}}$ indices were comparable between the two T1DM subgroups, whereas $\mathrm{SqT}_{\mathrm{s}}$ indices tended to be lower in patients with low versus high RR E/I ratios. Better discrimination between the two T1DM groups was observed when using baroreflex gain, as calculated during the squatting-standing transition, as this was significantly decreased in T1DM patients with low RR E/I ratios compared with those with high RR E/I ratios (1.39 \pm 1.39 vs $2.43 \pm 1.57 \mathrm{~ms} . \mathrm{mmHg}^{-1}$, respectively; $P=0.0374$; Table 2 ).

When T1DM patients were separated according to baroreflex gain (below vs above the median $1.60 \mathrm{~ms}^{\mathrm{mmHg}} \mathrm{mg}^{-}$ ${ }^{1}$ ), patients with a low baroreflex gain were characterized by significantly lower RR E/I ratios, higher pulsatile stress indices, greater squat-induced PP increases, and considerably higher mean and median microalbuminuria levels (Table 2, right).

\section{Discussion}

The present study results confirm that T1DM patients, after around 20-25 years of having the disease, are characterized by significantly reduced RR E/I ratios and baroreflex gain, two markers of CAN, and higher PP levels, increased PP $\times$ HR products and greater squat-associated PP rises, all of which are markers of pulsatile stress and arterial stiffness, compared with the corresponding values in matched non-diabetic subjects. Also, our present findings demonstrate that the classical CAN marker RR E/I ratio is able to separate patients with less postural tachycardia, delayed mean BP recovery and reduced baroreflex gain during the transition from squatting to standing (although no significant differences were observed in PP and pulsatile stress between the two T1DM subgroups when separated according to the sole RR E/I ratio). In addition, our present results show that the decreased baroreflex gain measured during the squat test in T1DM patients is associated with increased pulsatile stress and strongly associated with the presence of microalbuminuria.

The observation of higher PP levels in T1DM patients compared with controls in the age range of 25-60 years is in agreement with previous studies by our group demonstrating an earlier PP increase with age in this population $[17,24]$, and also with the observational data of the large cross-sectional case-control FinnDiane (Finnish Diabetic Nephropathy) study [9]. As PP is considered an indirect marker of arterial stiffness, the higher PP levels are consistent with accelerated vascular ageing in the T1DM population [8], especially in those with chronically poor glucose control [9,31]. In the EURODIAB Prospective Complications Study, PP was significantly associated with all-cause mortality, and a mean 12-mmHg higher PP was observed in T1DM patients who died 
versus those who survived [12]. The present study also confirms that the squatting position markedly increases $\mathrm{PP}$, and that this amplification phenomenon is considerably more marked (nearly doubled) in T1DM patients than in their age-matched controls, again in agreement with accelerated arterial stiffness [24].

Although our T1DM patients as a whole had significantly lower RR E/I ratios than the non-diabetic controls, no significant differences were observed in terms of the $\mathrm{SqT}_{\mathrm{v}}$ and $\mathrm{SqT}_{\mathrm{s}}$ indices calculated during the squat test, two proposed markers of parasympathetic and sympathetic dysfunction, respectively [22]. Previously, we observed altered $\mathrm{SqT}_{\mathrm{v}}$ and $\mathrm{SqT}_{\mathrm{s}}$ indices in T1DM patients compared with matched non-diabetic controls [25,26]. The absence of any differences in these markers between diabetic and non-diabetic subjects may be explained by the mode of selection of the T1DM patients in the present study, half of whom were recruited on the basis of a persistently maintained RR E/I ratio. Nevertheless, decreased baroreflex gain was observed in our T1DM patients, reflecting the presence of CAN after more than 20 years of diabetes and, thus, indicating an increased cardiovascular and total mortality risk [1,32]. T1DM patients with low versus high RR E/I ratios had almost the same duration of diabetes in the present study, confirming that diabetes duration does not sufficiently discriminate between patients with CAN and that other factors need to be taken into account. Despite the fact that only a slight (non-significant) difference could be detected in recent $\mathrm{HbA}_{1 \mathrm{c}}$ levels between the two T1DM subgroups with low and high RR E/I ratios, the quality of chronic glycaemic control most probably plays a role in the development of CAN [32-34].

Table 1: Characteristics of the patients with type 1 diabetes mellitus (T1DM) and non-diabetic healthy subjects (controls).

\begin{tabular}{|c|c|c|c|}
\hline & T1DM patients & Controls & $P$ \\
\hline \multicolumn{4}{|l|}{ Demographics } \\
\hline$n$ (male/female) & $20 / 20$ & $20 / 20$ & \\
\hline Age (years) & $46 \pm 10$ & $46 \pm 10$ & NS \\
\hline Body mass index $\left(\mathrm{kg} / \mathrm{m}^{2}\right)$ & $24.3 \pm 2.5$ & $24.2 \pm 2.6$ & 0.8740 \\
\hline \multicolumn{4}{|l|}{ Average 3-min measurements ${ }^{a}$} \\
\hline Mean BP (mmHg) & $81 \pm 10$ & $85 \pm 14$ & 0.1878 \\
\hline Systolic BP (mmHg) & $122 \pm 14$ & $121 \pm 19$ & 0.7657 \\
\hline Diastolic BP (mmHg) & $64 \pm 9$ & $68 \pm 12$ & 0.0990 \\
\hline PP (mmHg) & $58 \pm 13$ & $53 \pm 11$ & 0.0684 \\
\hline HR(beats.min ${ }^{-1}$ ) & $88 \pm 11$ & $82 \pm 10$ & 0.0167 \\
\hline $\mathrm{PP} \times$ HR product $\left(\mathrm{mmHg} \cdot \mathrm{min}^{-1}\right)$ & $5011 \pm 1112$ & $4303 \pm 994$ & 0.0040 \\
\hline \multicolumn{4}{|l|}{ Squatting-induced changes } \\
\hline Delta mean BP (mmHg) & $+13 \pm 9$ & $+6 \pm 6$ & 0.0002 \\
\hline Delta PP (mmHg) & $+13 \pm 9$ & $+7 \pm 6$ & 0.0007 \\
\hline Delta HR (beats.min ${ }^{-1}$ ) & $-6 \pm 7$ & $-5 \pm 8$ & NS \\
\hline \multicolumn{4}{|l|}{ Standing-induced changes } \\
\hline Max delta mean BP (mmHg) & $-13 \pm 13$ & $-7 \pm 7$ & 0.0112 \\
\hline Max delta HR (beats.min ${ }^{-1}$ ) & $+22 \pm 11$ & $+32 \pm 12$ & 0.0002 \\
\hline Delay to baseline mean BP recovery (s) & $28 \pm 18$ & $21 \pm 11$ & 0.0635 \\
\hline \multicolumn{4}{|l|}{ Indices of CAN } \\
\hline $\mathrm{RR}$ E/I ratio & $1.16 \pm 0.13$ & $1.29 \pm 0.14$ & 0.0018 \\
\hline $\mathrm{SqT}_{\mathrm{v}}$ index & $0.85 \pm 0.12$ & $0.82 \pm 0.13$ & 0.2779 \\
\hline $\mathrm{SqT}_{\mathrm{s}}$ index & $1.17 \pm 0.23$ & $1.22 \pm 0.11$ & 0.1573 \\
\hline Baroreflex gain (ms.mmHg-1) & $1.91 \pm 1.57$ & $3.90 \pm 3.23$ & 0.0011 \\
\hline
\end{tabular}

Data are expressed as means \pm SD. BP: blood pressure; PP: pulse pressure; HR: heart rate; NS: not significant; delta: difference between mean values (excluding transition phases) recorded in initial standing position and squatting; max delta: maximum change between levels measured at the end of squatting and early phase of standing; CAN: cardiovascular autonomic neuropathy; RR: R-R interval; E/I: expiration/inspiration; $S q T_{v}$ : 'vagal' index; $S q T_{s}$ : 'sympathetic' index. ${ }^{a}$ Recorded during the whole 3-min posture test. 
Fig. 1. Changes in mean arterial blood pressure (MBP), pulse pressure (PP) and heart rate (HR) during a posture test (1-min standing, 1-min squatting [grey zone], 1-min standing): (left) 40 patients with type 1 diabetes (T1DM; solid triangles) versus 40 non-diabetic controls (open triangles), matched for age, gender and body mass index; and (right) 20 patients with T1DM and low RR E/I ratios indicative of cardiovascular autonomic neuropathy (CAN) (solid circles) versus 20 patients with T1DM and high RR E/I ratios (open circles), matched for age, duration of diabetes, gender and body mass index.

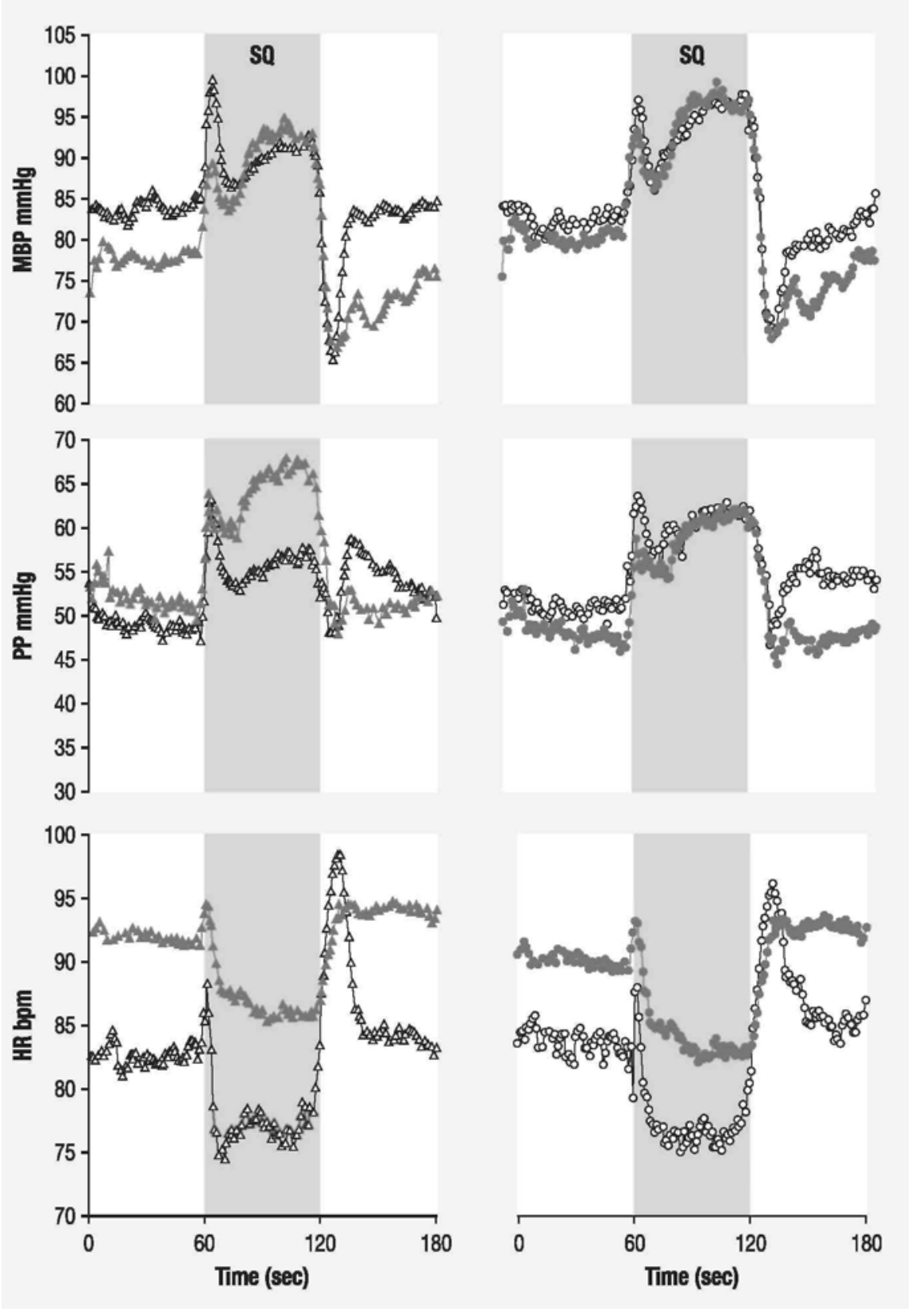

Table 2 : Characteristics of patients with type 1 diabetes mellitus (T1DM) according to RR E/I ratios (low vs high) and baroreflex gain (BRG) (below vs above median value of $1.60 \mathrm{~ms}^{\mathrm{mmHg}} \mathrm{Hg}^{-1}$ ).

\begin{tabular}{|c|c|c|c|c|c|}
\hline \multicolumn{3}{|c|}{ T1DM patients } & \multicolumn{3}{|c|}{ T1DM patients } \\
\hline $\begin{array}{l}\text { Low E/I } \\
\text { ratios } \\
\text { (range: }\end{array}$ & $\begin{array}{l}\text { High E/I } \\
\text { ratios } \\
\text { (range: }\end{array}$ & $P$ & $\begin{array}{l}\text { Low BRG } \\
\text { (range: } \\
0.19-1.57 \text { ) }\end{array}$ & $\begin{array}{l}\text { High BRG } \\
\text { (range: } \\
1.66-6.41 \text { ) }\end{array}$ & $P$ \\
\hline $1.02-1.09)$ & $1.16-1.49)$ & & & & \\
\hline
\end{tabular}

Demographics

$n$ (male/female)

$10 / 10$

10/10

NS

$10 / 11$

$11 / 9$ 


\begin{tabular}{|c|c|c|c|c|c|c|}
\hline Age (years) & $46 \pm 10$ & $46 \pm 9$ & 0.9887 & $47 \pm 9$ & $45 \pm 10$ & 0.5377 \\
\hline Diabetes duration (years) & $26 \pm 8$ & $22 \pm 8$ & 0.1411 & $25 \pm 7$ & $23 \pm 10$ & 0.4829 \\
\hline BMI $\left(\mathrm{kg} / \mathrm{m}^{2}\right)$ & $24.4 \pm 2.8$ & $23.9 \pm 2.4$ & 0.5121 & $23.8 \pm 2.9$ & $24.6 \pm 2.3$ & 0.3447 \\
\hline $\mathrm{HbA}_{1 \mathrm{c}}(\%)$ & $8.9 \pm 1.1$ & $8.5 \pm 1.4$ & 0.3823 & $9.0 \pm 1.1$ & $8.2 \pm 1.3$ & 0.0628 \\
\hline \multicolumn{7}{|l|}{ Microalbuminuria } \\
\hline Mean values (mg/L) & $90 \pm 155$ & $42 \pm 128$ & \multirow[t]{2}{*}{0.3039} & $119 \pm 183$ & $8 \pm 8$ & \multirow[t]{2}{*}{0.0137} \\
\hline Median [interquartile] values (mg/L) & $13[4-57]$ & $7[4-15]$ & & $20[6-82]$ & $4[4-11]$ & \\
\hline \multicolumn{7}{|l|}{ Average 3-min measurements" } \\
\hline Mean BP (mmHg) & $81 \pm 10$ & $82 \pm 9$ & 0.5533 & $82 \pm 9$ & $81 \pm 10$ & 0.8483 \\
\hline Systolic BP (mmHg) & $120 \pm 15$ & $124 \pm 14$ & 0.4666 & $125 \pm 14$ & $119 \pm 14$ & 0.1806 \\
\hline Diastolic BP (mmHg) & $64 \pm 9$ & $64 \pm 8$ & 0.9033 & $64 \pm 7$ & $64 \pm 10$ & 0.9059 \\
\hline PP (mmHg) & $56 \pm 13$ & $60 \pm 12$ & 0.3587 & $61 \pm 14$ & $54 \pm 11$ & 0.0962 \\
\hline HR(beats. $\left.\min ^{-1}\right)$ & $90 \pm 13$ & $85 \pm 7$ & 0.1775 & $88 \pm 12$ & $87 \pm 10$ & 0.6020 \\
\hline $\mathrm{PP} \times$ HR product $\left(\mathrm{mmHg} \cdot \mathrm{min}^{-1}\right)$ & $4947 \pm 1150$ & $5075 \pm 1070$ & 0.7243 & $5344 \pm 1219$ & $4643 \pm 840$ & 0.0445 \\
\hline \multicolumn{7}{|l|}{ Squatting-induced changes } \\
\hline Delta mean BP (mmHg) & $+14 \pm 9$ & $+12 \pm 9$ & 0.4979 & $+18 \pm 9$ & $+7 \pm 5$ & 0.0001 \\
\hline Delta PP (mmHg) & $+13 \pm 9$ & $+12 \pm 8$ & 0.5543 & $+16 \pm 10$ & $+9 \pm 6$ & 0.0095 \\
\hline Delta HR (beats.min ${ }^{-1}$ ) & $-7 \pm 7$ & $-6 \pm 8$ & 0.9003 & $-5 \pm 8$ & $-8 \pm 6$ & 0.3193 \\
\hline \multicolumn{7}{|l|}{ Standing-induced changes } \\
\hline Max delta mean BP (mmHg) & $-42 \pm 17$ & $-38 \pm 11$ & 0.4105 & $-47 \pm 17$ & $-32 \pm 8$ & 0.0013 \\
\hline Max delta HR (beats.min ${ }^{-1}$ ) & $+18 \pm 13$ & $+25 \pm 6$ & 0.0317 & $+19 \pm 13$ & $+24 \pm 7$ & 0.0186 \\
\hline Delay to baseline mean BP recovery (s) & $33 \pm 19$ & $22 \pm 15$ & 0.0493 & $32 \pm 21$ & $22 \pm 11$ & 0.0691 \\
\hline \multicolumn{7}{|l|}{ Indices of CAN } \\
\hline RR E/I ratio & $1.05 \pm 0.02$ & $1.27 \pm 0.10$ & 0.00001 & $1.12 \pm 0.12$ & $1.21 \pm 0.13$ & 0.0308 \\
\hline $\mathrm{SqT}_{\mathrm{v}}$ index & $0.85 \pm 0.11$ & $0.85 \pm 0.13$ & 0.9558 & $0.86 \pm 0.10$ & $0.85 \pm 0.13$ & 0.7906 \\
\hline $\mathrm{SqT}_{\mathrm{s}}$ index & $1.10 \pm 0.09$ & $1.23 \pm 0.29$ & 0.0777 & $1.12 \pm 0.15$ & $1.21 \pm 0.28$ & 0.2336 \\
\hline BRGtms.mmHg ${ }^{-1}$ ) & $1.39 \pm 1.39$ & $2.43 \pm 1.57$ & 0.0374 & $0.82 \pm 0.41$ & $3.12 \pm 1.50$ & $<0.0001$ \\
\hline $\begin{array}{l}\text { measured at the end of squatting and early phase } \\
\text { expiration/inspiration; } \mathrm{SqT}_{\mathrm{v}} \text { : 'vagal' index, the } \mathrm{r} \text {. }\end{array}$ & ure; PP: pulse pr & ssure; HR: heart & & & lifference betwe & \\
\hline
\end{tabular}

There may also be links between PP and CAN [24], between aortic stiffness and CAN [13,14], and between arterial stiffness, cardiovagal baroreflex sensitivity and postural BP changes [35]. Increased SBP was identified as a factor associated with an increased risk of developing CAN in the cohort of T1DM patients in the EURODIAB Prospective Complications Study [16]. Also, we previously reported a significant inverse relationship between pulsatile stress and baroreflex gain as a marker of CAN in middle-aged patients with T1DM [26]. In the present study, such a significant inverse correlation was observed between the pulsatile stress index and baroreflex gain in the overall population tested, whereas no such correlations were observed between pulsatile stress and RR E/I ratios. Several mechanisms may underlie the association between arterial stiffness and impaired cardiovagal baroreflex sensitivity. Increased intima-media thickness at the site of baroreceptors, reduced vascular distensibility, endothelial dysfunction and impaired cardiac function can all contribute to cardiovascular autonomic dysfunction [15]. More specifically, stiffness of the carotid arteries and the aorta, where the arterial baroreceptors are located, can affect stretch-sensitive receptors and, thus, baroreflex sensitivity [35].

Both CAN and arterial stiffness abnormalities have been shown to be closely associated with the presence of (micro)albuminuria, regarded as a reflection of endothelial dysfunction or vascular damage in diabetics [15]. Early renal alterations are also related to pulsatile stress [30]. In T1DM, the odds ratio of CAN has been shown to increase with SBP, hypertension, $\mathrm{HbA}_{1 \mathrm{c}}$ and microalbuminuria [36]. Baroreflex sensitivity was reduced in T1DM patients with microalbuminuria, but without CAN on standard Ewing tests [37]. This suggests that baroreflex sensitivity may be affected at an earlier stage and may be considered a better predictor of other vascular damage. In the present study, a strong relationship was observed between the decreased baroreflex gain (but with no decreased RR E/I ratios) assessed during the squat test and the presence of microalbuminuria. In one prospective study, the progression of autonomic dysfunction in relation to nephropathy was followed for 14 years in T1DM patients [38]. Multiple regression analyses showed that the association between autonomic dysfunction and future albuminuria was due to the RR E/I ratio, supporting a role for this simple marker in routine clinical practice. In contrast to previous studies [36], only a trend was observed in the present study between higher microalbuminuria levels and the presence of CAN, as detected by low RR E/I ratios. This may 
have been due to the relatively small number of subjects with microalbuminuria, which could be explained by the fact that T1DM patients with hypertension were excluded from our present study, whereas recent observational data have favoured the role of CAN in hypertension of T1DM patients [39]. Furthermore, the association of the CAN/hypertension profile with vascular complications is consistent with deleterious effects on vascular haemodynamics and structure in addition to the effects of hypertension itself. CAN was also shown to be associated with the presence of retinopathy, which supports a role of poor glycaemic control in CAN development [34]; it has also been suggested that an impairment of autonomic peripheral blood-flow control might be a contributing factor in the formation of microvascular lesions [33].

Some limitations of the present study need to be mentioned. First, only a single test was used from the battery of tests proposed by Ewing to assess CAN [5] —namely, the RR E/I ratio, as measured by a deep-breathing manoeuvre. Although CAN is classically diagnosed by having at least three abnormal tests out of five [1,5], it should be recognized that all five tests are rarely performed at bedside in routine clinical practice [4]. In a recent statement by the Toronto Diabetic Neuropathy Expert Group [4], it was suggested that the presence of one abnormal cardiovagal test identifies possible or early CAN, and that at least two abnormal HR tests are required for a definite or confirmed diagnosis of CAN. Nevertheless, several studies have pointed out that the RR E/I ratio is a simple, but especially informative, marker of CAN [6,38], and has the greatest specificity [4]. In addition, orthostatic hypotension (asymptomatic or symptomatic) along with HR test abnormalities (resulting in a decreased baroreflex gain in the present study) indicate more severe or advanced CAN [4].

Another study limitation was that, as our patients were perfectly matched for age (mean: 46 years; range: 25-60 years) on comparing T1DM patients with controls and T1DM patients with low versus high R-R E/I ratios, age was not taken into account when considering RR E/I ratios as abnormal in our preliminary analysis. Additional analyses showed that adjusting for age did not change the conclusions of the study (indeed, in the group with high RR E/I ratios, only one rather young [27-year-old] T1DM patient had a relatively low value for age [1.17] whereas, in the group with low RR E/I ratios, only one older T1DM patient [aged 58 years] had a somewhat high value for age [1.09]).

Yet another limitation was that several studies have demonstrated that absolute brachial and finger PP measurements do not necessarily equate, with larger differences in SBP; indeed, the differences are generally small and not considered to be of clinical relevance [29]. Furthermore, some studies have shown good concordance between peripheral (finger, as in the present study) and central (aortic, now recognized as the most important risk factor) BP measurements [40]. Nevertheless, PP measured at the finger site may not necessarily reflect central PP because of the amplification phenomenon.

Moreover, glucose control in the T1DM patients evaluated in the present study was far from optimal, despite intensified insulin therapy. For this reason, our present results may not necessarily be extrapolated to patients with near-normal glycaemia of many years' duration, as chronic hyperglycaemia appears to play a major role in accelerating both arterial stiffness [31] and CAN [2,32,33]. Finally, plasma glucose levels were not recorded at the time of the dynamic tests in our T1DM patients.

\section{Conclusion}

Patients with long-duration T1DM, compared with matched non-diabetic controls, present with both CAN abnormalities and markers of increased pulsatile stress, two independent risk factors of premature cardiovascular disease and mortality. T1DM patients with low RR E/I ratios exhibit lower levels of orthostatic reflex tachycardia and baroreflex gain, and are prone to more prolonged orthostatic hypotension. Also, separation of the T1DM population according to RR E/I index alone did not result in different markers of pulsatile stress in contrast to the use of squatting-derived baroreflex gain, which was strongly associated with microalbuminuria.

\section{Author contributions}

J.C.P., M.M. and A.J.S. made substantial contributions to the concept and design of the study and outlined the structure of the report. J.C.P. and M.M. were involved in the acquisition, analysis and interpretation of the data. A.J.S. had full access to all the data, wrote the report and had final responsibility for the decision to submit for publication. All authors critically reviewed the reports and approved the final version of the report for submission.

\section{Disclosure of interest}

The authors declare that they have no conflicts of interest concerning this article.

\section{Acknowledgements}

This work was supported by an unrestricted research grant from Novo Nordisk Belgium. The study was also presented in abstract form as a poster at the Congrès de la Société Francophone du Diabète (Congress of the 
Published in : Diabetes \& Metabolism

Status : Postprint (Author's)

French-Speaking Diabetes Society) held in Geneva, Switzerland, March 22-25, 2011.

\section{References}

[1] Vinik AI, Ziegler D. Diabetic cardiovascular autonomic neuropathy. Circulation 2007;115:387-97.

[2] Retnakaran R, Zinman B. Type 1 diabetes, hyperglycaemia, and the heart. Lancet 2008;371:1790-9.

[3] Pop-Busui R. Cardiac autonomic neuropathy in diabetes: a clinical perspective. Diabetes Care 2010;33:434-41.

[4] Tesfaye S, Boulton AJ, Dyck PJ, Freeman R, Horowitz M, Kempler P, et al. Diabetic neuropathies: update on definitions, diagnostic criteria, estimation of severity, and treatments. Diabetes Care 2010;33:2285-93.

[5] Ewing DJ, Martin CN, Young RJ, Clarke BF. The value of cardiovascular autonomic function tests: 10 years experience in diabetes. Diabetes Care 1985;8:491-8.

[6] May O, Arildsen H. Assessing cardiovascular autonomic neuropathy in diabetes meilitus: how many tests to use? J Diabetes Complications 2000;14:7-12.

[7] Valensi P, Paries J, Attali JR, French Group for Research and Study of Diabetic Neuropathy. Cardiac autonomic neuropathy in diabetic patients: influence of diabetes duration, obesity, and microangiopathic complications - the French multicenter study. Metabolism 2003;52:815-20.

[8] Benetos A. Pulse pressure and arterial stiffness in type 1 diabetic patients. J Hypertens 2003;21:2005-7.

[9] Ronnback M, Fagerudd J, Forsblom C, Pettersson-Fernholm K, Reunanen A, Groop PH. Altered age-related blood pressure pattern in type 1 diabetes. Circulation 2004;110:1076-82.

[10] Maser RE, Mitchell BD, Vinik AI, Freeman R. The association between cardiovascular autonomic neuropathy and mortality in individuals with diabetes: a meta-analysis. Diabetes Care 2003;26:1895-901.

[11] Schram MT, Chaturvedi N, Fuller JH, Stehouwer CD, EURODIAB Prospective Complications Study Group. Pulse pressure is associated with age and cardiovascular disease in type 1 diabetes : the Eurodiab Prospective Complications Study. J Hypertens 2003;21:2035-44.

[12] Soedamah-Muthu SS, Chaturvedi N, Witte DR, Stevens LK, Porta M, Fuller JH. Relationship between risk factors and mortality in type 1 diabetic patients in Europe. The EURODIAB Prospective Complications Study (PCS). Diabetes Care 2008;31:1360-6.

[13] Ahlgren AR, Sundkvist G, Wollmer P, Sonesson B, Länne T. Increased aortic stiffness in women with type 1 diabetes meilitus is associated with diabetes duration and autonomic nerve function. Diabet Med 1999;16:291-7.

[14] Prince CT, Secrest AM, Mackey RH, Arena VC, Kingsley LA, Orchard TJ. Cardiovascular autonomic neuropathy, HDL cholesterol, and smoking correlate with arterial stiffness markers determined 18 years later in type 1 diabetes. Diabetes Care 2010;33:652-7.

[15] Lefrandt JD, S mit AJ, Zeebregts CJ, Gans RO, Hoogenberg KH. Autonomic dysfunction in diabetes: a consequence of cardiovascular damage. Curr Diabetes Rev 2010;6:348-58.

[16] Witte DR, Tesfaye S, Chaturvedi N, Eaton SE, Kempler P, Fuller JH. Risk factors for cardiac autonomic neuropathy in type 1 diabetes meilitus. Diabetologia 2005;48:164-71.

[17] Philips JC, Marchand M, Scheen AJ. Pulse pressure and cardiovascular autonomic neuropathy according to duration of type 1 diabetes. Diabetes Metab Res Rev 2009;25:442-51.

[18] Purewal TS, Watkins PJ. Postural hypotension in diabetic autonomic neuropathy: a review. Diabet Med 1995;12:192-200.

[19] Hirai FE, Moss SE, Klein BE, Klein R. Postural blood pressure changes and associated factors in long-term type 1 diabetes: Wisconsin Epidemiologic Study of Diabetic Retinopathy. J Diabetes Complications 2009;23: 83-8.

[20] Scheen AJ, Juchmes J, Pochet T. Non invasive, beat-to-beat, investigation of the effects of posture on arterial blood pressure in diabetic neuropathy. Diabete Metab 1990;16:382-4.

[21] Philips JC, Scheen AJ. Squatting test: a posture to study and counteract cardiovascular abnormalities associated with autonomic dysfunction. Auton Neurosci 2011;162:3-9.

[22] Marfella R, Giugliano D, Di Maro G, Acampora R, Giunta R, D'Onofrio F. The squatting test: a useful tool to assess both parasympathetic and sympathetic involvement of the cardiovascular autonomic neuropathy in diabetes. Diabetes 1994;43:607-12.

[23] Nakagawa M, Shinohara T, Anan F, Yufu K, Takahashi N, et al. New squatting test indices are useful for assessing baroreflex sensitivity in diabetes meilitus. Diabet Med 2008;25:1309-15.

[24] Philips JC, Marchand M, Scheen AJ. Squatting amplifies pulse pressure increase according to duration of type 1 diabetes. Diabetes Care 2008;31:322-4.

[25] Philips JC, Marchand M, Scheen AJ. Changes in pulse pressure, heart rate and double product during squatting in type 1 diabetes according to age. Diabet Med 2010;27:753-61.

[26] Philips JC, Marchand M, Scheen AJ. Pulsatile stress in middle-aged patients with type 1 or type 2 diabetes compared to nondiabetic controls. Diabetes Care 2010;33:2424-9.

[27] Scheen AJ, Philips JC. Squatting test: a dynamic postural manoeuvre to study baroreflex sensitivity. Clin Auton Res 2011, doi:10.1007/s10286-011-0140-8.

[28] Rickards CA, Newman DG. A comparative assessment of two techniques for investigating initial cardiovascular reflexes under acute orthostatic stress. Eur J Appl Physiol 2003;90:449-57.

[29] Imholz BP, Wieling W, van Montfrans GA, Wesseling KH. Fifteen years experience with finger arterial pressure monitoring: 
assessment of the technology. Cardiovasc Res 1998;38:605-16.

[30] Baumann M, Pan CR, Roos M, von Eynatten M, Sollinger D, Lutz J, et al. Pulsatile stress correlates with (micro-)albuminuria in renal transplant recipients. Transpl Int 2010;23:292-8.

[31] Schram MT, Schalkwijk CG, Bootsma AH, Fuller JH, Chaturvedi N, Stehouwer CD. Advanced glycation end products are associated with pulse pressure in type 1 diabetes: the EURODIAB Prospective Complications Study. Hypertension 2005;46:232-7.

[32] Pop-Busui R, Low PA, Waberski BH, Martin CL, Albers JW, Feld-man EL, et al. Effects of prior intensive insulin therapy on cardiac autonomic nervous system function in type 1 diabetes meilitus: the Diabetes Control and Complications Trial/Epidemiology of Diabetes Interventions and Complications study (DCCT/EDIC). Circulation 2009; 119: 2886-93.

[33] Valensi P, Huard JP, Giroux C, Attali JR. Factors involved in cardiac autonomic neuropathy in diabetic patients. J Diabetes Complications 1997;11:180-7.

[34] Pavy-Le Traon A, Fontaine S, Tap G, Guidolin B, Senard JM, Hanaire H. Cardiovascular autonomic neuropathy and other complications in type 1 diabetes. Clin Auton Res 2010;20:153-60.

[35] Mattace-Raso FU, van den Meiracker AH, Bos WJ, van der Cammen TJ, Westerhof BE, Elias-Smale S, et al. Arterial stiffness, cardiovagal baroreflex sensitivity and postural blood pressure changes in older adults: the Rotterdam Study. J Hypertens 2007;25:1421-6.

[36] Voulgari C, Psallas M, Kokkinos A, Argiana V, Katsilambros N, Tentolouris N. The association between cardiac autonomic neuropathy with metabolic and other factors in subjects with type 1 and type 2 diabetes. J Diabetes Complications 2011;25:159-67.

[37] Lefrandt JD, Hoogenberg K, van Roon AM, Dullaart RP, Gans RO, Smit AJ. Baroreflex sensitivity is depressed in microalbuminuric type 1 diabetic patients at rest and during sympathetic manoeuvres. Diabetologia 1999;42:1345-9.

[38] Forsén A, Kangro M, Sterner G, Norrgren K, Thorsson O, Wollmer P, et al. A 14-year prospective study of autonomic nerve function in Type 1 diabetic patients: association with nephropathy. Diabet Med 2004;21:852-8.

[39] Ayad F, Belhadj M, Pariés J, Attali JR, Valensi P. Association between cardiac autonomic neuropathy and hypertension and its potential influence on diabetic complications. Diabet Med 2010;27: 804-11.

[40] Eckert S, Horstkotte D. Comparison of Portapres non-invasive blood pressure measurement in the finger with intra-aortic pressure measurement during incremental bicycle exercise. Blood Press Monit 2002;7: 179-83. 